\title{
Accounting of geomechanical layer properties in multi-layer oil field development
}

\author{
Sergey V. GALKIN ${ }^{1}$, Sergey N. KRIVOSHCHEKOV ${ }^{1}$, Nikita D. KOZYREV ${ }^{1}$, Alexander A. KOCHNEV ${ }^{1}$, \\ Alexander G. MENGALIEV ${ }^{2}$ \\ ${ }^{1}$ Perm National Research Polytechnic University, Perm, Russia \\ ${ }^{2}$ Branch of LLC LUKOIL-Engineering PermNIPIneft, Perm, Russia
}

How to cite this article: Galkin S.V., Krivoshchekov S.N., Kozyrev N.D., Kochnev A.A., Mengaliev A.G. Accounting of geomechanical layer properties in multi-layer oil field development. Journal of Mining Institute. 2020. Vol. 244, p. 408-417. DOI: 10.31897/PMI.2020.4.3

\begin{abstract}
Amid the ever-increasing urgency to develop oil fields with complex mining and geological conditions and low-efficiency reservoirs, in the process of structurally complex reservoir exploitation a number of problems arise, which are associated with the impact of layer fractures on filtration processes, significant heterogeneity of the structure, variability of stress-strain states of the rock mass, etc. Hence an important task in production engineering of such fields is a comprehensive accounting of their complex geology. In order to solve such problems, the authors suggest a methodological approach, which provides for a more reliable forecast of changes in reservoir pressure when constructing a geological and hydrodynamic model of a multi-layer field. Another relevant issue in the forecasting of performance parameters is accounting of rock compressibility and its impact on absolute permeability, which is the main factor defining the law of fluid filtration in the productive layer.

The paper contains analysis of complex geology of a multi-layer formation at the Alpha field, results of compression test for 178 standard core samples, obtained dependencies between compressibility factor and porosity of each layer. By means of multiple regression, dependencies between permeability and a range of parameters (porosity, density, calcite and dolomite content, compressibility) were obtained, which allowed to take into account the impact of secondary processes on the formation of absolute permeability. At the final stage, efficiency of the proposed methodological approach for construction of a geological and hydrodynamic model of an oil field was assessed. An enhancement in the quality of well-by-well adaptation of main performance parameters, as well as an improvement in predictive ability of the adjusted model, was identified.
\end{abstract}

Key words: geomechanical properties; pore space compressibility; geological and hydrodynamic model; structurally complex reservoir; absolute permeability; effective pressure; oil field; multi-layer field

Acknowledgements: This research has been performed under financial support of the Ministry of Science and Higher Education of the Russian Federation (project N FSNM-2020-0027).

Introduction. Currently, the majority of large hydrocarbon fields are in the late stages of development. Therefore, development of fields with hard-to-recover reserves, including multi-layer formations with structurally complex reservoirs, becomes more topical. Such layers are characterized by significant heterogeneity, fractures, disjunctive faults, which taken together exert a significant influence on the processes of fluid filtration in the reservoir system [5]. Production engineering requires a comprehensive approach to the accounting of field geological data [3].

In accordance with regulatory documents [7], a mandatory requirement of project decisionmaking in the development of oil production facilities is the construction of permanent geological \&technological models (PGTMs). One of the main objectives of the PGTMs is prediction of oil and gas extraction rates in the short and long term. However, the process of PGTM construction for structurally complex reservoirs is marked by uncertainties, associated with underestimation of the following geological features: secondary processes (karsting, dolomitization, fracture formation), influence of changes in the effective pressure on the voids of reservoir rocks, abnormally high reservoir pressure and stress values in the tectonic fault zones. Studies $[15,16]$ present results of core tests, demonstrating a different character of porosity and permeability variations, when stress state of the rocks results from stress load.

There is research targeted at the construction of models, which allow to take into account geological structure, fluid filtration processes and layer geomechanics. In the framework of study [1], 
a geomechanical model is developed in order to optimize well construction under abnormally high reservoir pressure by using high-precision seismic monitoring. Paper [8] provides an analysis of main problems, associated with the development of such models: absence of a one-size-fits-all geological and geomechanical simulator for creation of 4D geomechanical models; time-consuming calculations (even with high-performance computers they take up to six days). In study [4], in order to construct a mathematical model, the authors developed a method to calculate oil filtration into the well taking into account dependency of filtration properties on the stress-strain state. In paper [2] in order to design hydraulic fracturing of the reservoir, a hydrodynamic model took into account geomechanical properties by assigning a dependency between permeability and pressure variation.

Analysis of studies in this subject area demonstrates the absence of methodological approach to the construction of a geological and hydrodynamic model, which would take into account geomechanical properties and provide high predictive ability without loss of computational speed. In this paper the authors propose a comprehensive approach to the construction of a hydrodynamic model of an oil field, which includes a detailed analysis of core sample test results, statistical data processing, plotting of correlation dependencies between parameters, revision of reservoir geology, permeability redistribution and accounting of geomechanical rock properties.

Methodology. The Alpha oil field, located in the Denisov Depression of the Timan-Pechora Basin, was selected as the research object. The oil field is multi-layer, characterized by complex geology, development of secondary processes in carbonate reservoirs. The reservoir was formed in the course of four reef-construction cycles: the first Zadonian $\left(\mathrm{D}_{3} \mathrm{fm}_{1}(\mathrm{zd})\right)$ and three Yelets ones $\left(\mathrm{D}_{3} \mathrm{fm}_{1}(\mathrm{el})\right)$. Rocks of the first cycle are separated from the later ones by a dense but relatively fragile bridge, 3-55 m thick. The formation of Zadonian sediments is characterized as layer-massive, domeshaped, and lithologically sealed. The formation of Yelets sediments is layer-massive, lithologically screened with a horizontal oil-water contact at different levels, complicated by multi-facies zones. The void space of Zadonian and Yelets sediments is mostly composed of solution pores and cavities, pores of dolomitization and recrystallization.

A brief geological and physical description of the productive layers at the Alpha oil field is presented below:

\begin{tabular}{|c|c|c|}
\hline Parameter & $\mathrm{D}_{3} \mathrm{fm}_{1}(\mathrm{el})$ & $\mathrm{D}_{3} \mathrm{fm}_{1}(\mathrm{zd})$ \\
\hline Formation type & Layer-massive & Layer-massive, dome-shaped \\
\hline Reservoir type & Porous, cavity-porous & Porous, cavity-porous \\
\hline Average net oil-bearing thickness, $\mathrm{m}$ & $28.5^{\circ}$ & $7.6^{\circ}$ \\
\hline Porosity factor, unit fractions & 0.08 & 0.07 \\
\hline Oil saturation factor, unit fractions & 0.79 & 0.70 \\
\hline Average permeability, $\mu \mathrm{m}^{2}$ & 0.0930 & 0.0243 \\
\hline Net-sand-to-gross ratio, unit fractions & 0.41 & 0.43 \\
\hline Stratification, units & 13.2 & 4.1 \\
\hline Initial reservoir pressure, $\mathrm{MPa}$ & 40.1 & 39.9 \\
\hline In-situ oil viscosity, MPa·s & 0.564 & 0.550 \\
\hline Oil density at the surface, $t / \mathrm{m}^{3}$ & 0.825 & 0.833 \\
\hline Formation volume factor, unit fractions & 1.38 & 1.47 \\
\hline Gas saturation pressure, MPa & 22.35 & 21.60 \\
\hline Gas content, $\mathrm{m}^{3} / \mathrm{t}$ & 180.8 & 201.7 \\
\hline (Water) displacement efficiency, unit fractions & 0.458 & 0.395 \\
\hline
\end{tabular}

Reef reservoirs of the first Yelets sequence are characterized by high filtration and volumetric properties: porosity of $0.036-0.296$, permeability of $0.001-18.1 \mu \mathrm{m}^{2}$. At the current stage of production engineering, reservoirs of the second Yelets sequence are considered non-commercial. For the third Yelets sequence, filtration and volumetric characteristics of reef facies zone reservoirs are slightly lower than for the first one with porosity of $0.036-0.205$ and permeability of $0.001-9.1 \mu \mathrm{m}^{2}$. In the zone of backreef plume, deterioration of filtration and volumetric properties compared to the rest of the third Yelets sequence is observed: porosity of $0.036-0.182$, permeability of $0.001-1.1 \mu \mathrm{m}^{2}$. 
The Alpha oil field is at the first stage of the development, with the total of 36 wells drilled and average oil production rate amounting to 208 tons/day. At the current stage of the development, a decision was made to advance with the formation of Yelets sediments using a uniform well grid. A possibility of simultaneous separate exploitation is under consideration. Zadonian sediments are being developed with the use of a separate well grid due to significant difference in their filtration and volumetric properties. Development of this multi-layer system is complicated by complex geology, presence of cavities and fractures, low impact of the zone behind the perimeter, which led to declining energy state and, as a result, to a $14 \%$ annual decrease in liquid yield. Results of hydrodynamic studies demonstrated a $17 \%$ decline of productivity compared to the initial value, i.e., by $146.2 \mathrm{~m}^{3} /($ day $\cdot \mathrm{MPa})$. The system of reservoir pressure maintenance at the Alpha field is at the initial stage of development.

It should be noted that in the development of similar oil reservoirs, a significant impact on redistribution of reservoir pressure and, therefore, on filtration processes is exerted by elastic properties of the rock mass. As the pressure in the productive layer drops, effective pressure increases, which leads to compression of the productive layer by the weight of overlying rocks. The geological and hydrodynamic model takes into account elastic properties using a factor of pore space compressibility, which characterizes changes in pore space depending on reservoir pressure. In the PGTM pore space compressibility is often assigned a single average value for the entire formation.

In order to clarify the geological and hydrodynamic models of oil and gas reservoirs, this research provides an overview of the approach that allows to perform bulk discretization of pore space compressibility with the help of core tests analysis, thereby taking into account heterogeneity of rock properties, which significantly influences the processes of oil and gas field development. At the first stage, general dynamics of reservoir pressure was analyzed for the layers in question (Fig.1).

It was identified that throughout the whole time of well exploitation, reservoir pressure decreased on average by $26.3 \mathrm{MPa}(34 \%)$ compared to the initial level (40.3 MPa under saturation pressure of $22.5 \mathrm{MPa}$ ). According to the principles of rational development, reservoir pressure is not allowed to drop below saturation pressure; therefore, the interval of effective pressure under given values of initial and saturation pressure is calculated as follows:

$$
P_{\text {eff }}=P_{\mathrm{o}}-P_{\text {res, }}
$$

where $P_{\mathrm{o}}$ is overburden pressure, $\mathrm{MPa} ; P_{\text {res }}$ is reservoir pressure, MPa.

Drawing from formula (1) and assuming that average $P_{\mathrm{o}}$ for current depth equals $74 \mathrm{MPa}$, the maximum permissible range of variation for effective pressure is $34-52 \mathrm{MPa}$.

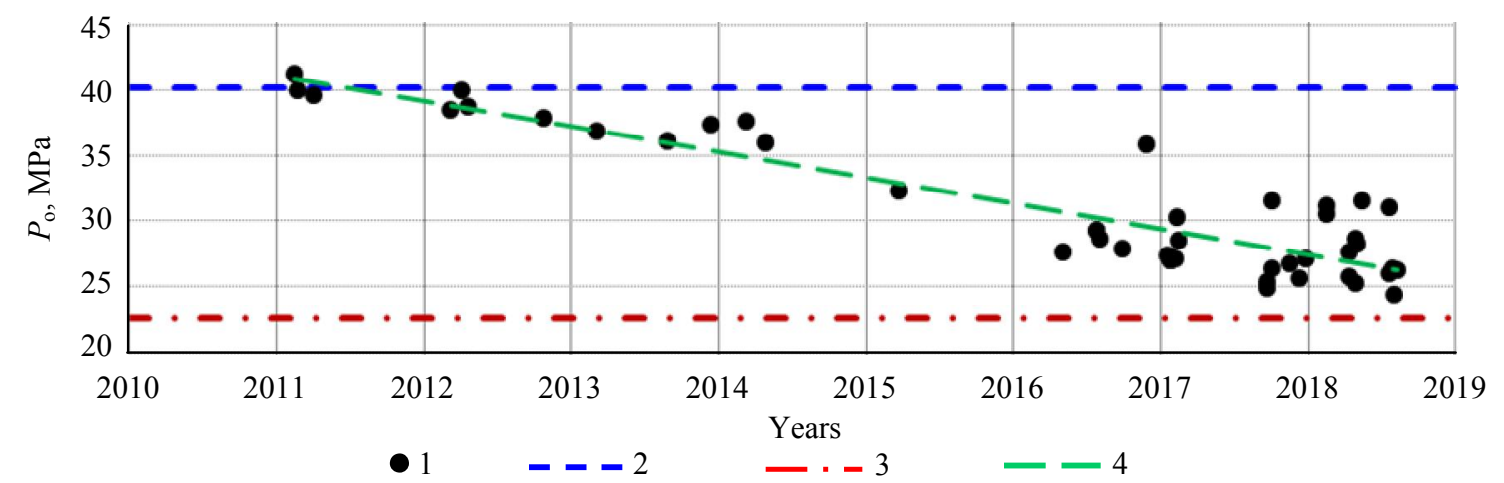

Fig.1. Dynamics of reservoir pressure across all wells of the oil field over the period of exploitation

1 - reservoir pressure $P_{\mathrm{res}}, \mathrm{MPa} ; 2$ - initial reservoir pressure $P_{\mathrm{in}}=40.3 \mathrm{MPa}$;

3 - saturation pressure $P_{\text {sat }}=21.8 \mathrm{MPa} ; 4$ - linear trend line of $P_{\text {res }}, \mathrm{MPa}$ 
The following is an analysis of compression tests of 178 core samples from $\mathrm{D}_{3} \mathrm{fm}_{1}(\mathrm{zd})$, $\mathrm{D}_{3} \mathrm{fm}_{1}\left(\mathrm{el}_{1}\right)$ and $\mathrm{D}_{3} \mathrm{fm}_{1}\left(\mathrm{el}_{3}\right)$ layers. Fig. 2 presents a compression curve in the case of a standard sample from $\mathrm{D}_{3} \mathrm{fm}_{1}\left(\mathrm{el}_{1}\right)$ layer. As effective pressure increases from 1 to $52 \mathrm{MPa}$, porosity varies from 0.189 to 0.167 , relative change in porosity equals $12 \%$.

Basing on the data from compression tests of each core sample for the considered interval of effective pressures, a derivative of relative change in porosity with respect to effective pressure was calculated. This derivative is a factor of pore space compressibility.

Then dependencies of pore space compressibility factor on open porosity were plotted for each layer under reservoir conditions (Fig.3). As a result, the following dependencies of compressibility $\beta$ on porosity $\mathrm{K}_{\mathrm{por}}, \mu \mathrm{m}^{2} \cdot 10^{-3}$ were obtained for each layer:

$$
\begin{gathered}
\mathrm{D}_{3} \mathrm{fm}_{1}\left(\mathrm{el}_{1}\right): \beta=0.0001 \mathrm{~K}_{\mathrm{por}}-0.61 \text { at } R^{2}=0.59 ; \\
\mathrm{D}_{3} \mathrm{fm}_{1}\left(\mathrm{el}_{3}\right): \beta=0.000175 \mathrm{~K}_{\mathrm{por}}-0.600953 \text { at } R^{2}=0.61 ; \\
\mathrm{D}_{3} \mathrm{fm}_{1}(\mathrm{zd}): \beta=0.00007 \mathrm{~K}_{\text {por }}-0.91057 \text { at } R^{2}=0.50 .
\end{gathered}
$$

These dependencies show that the highest compressibility factor is observed at low porosity values. Core samples with porosity below 0.036 are classified as consolidated (sub-tight) rocks.

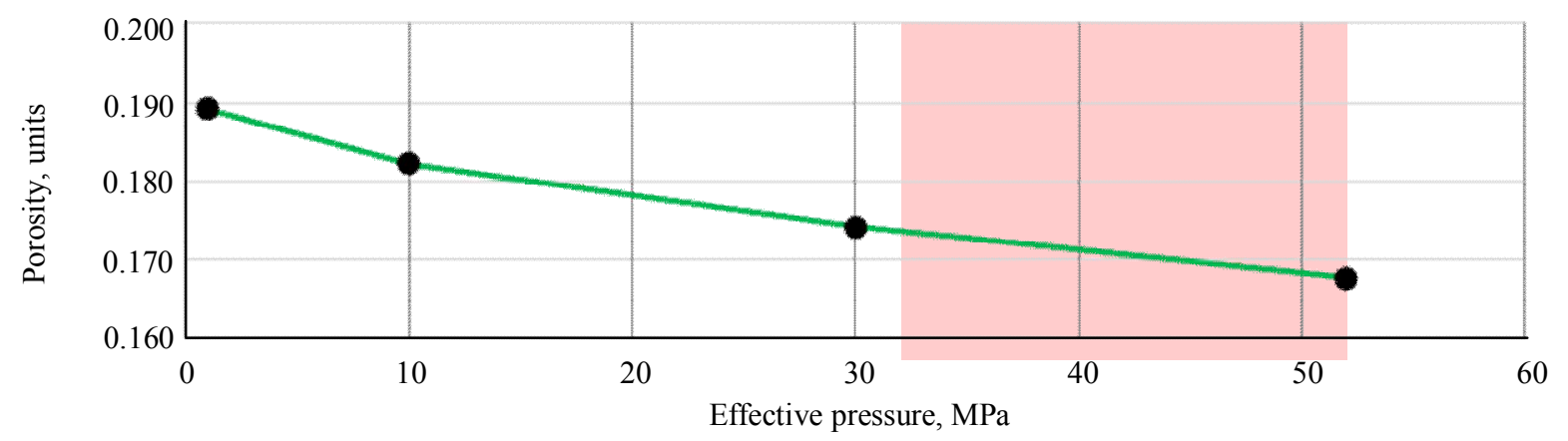

Acceptable range of effective pressure

Fig.2. Compression curve of a standard core sample

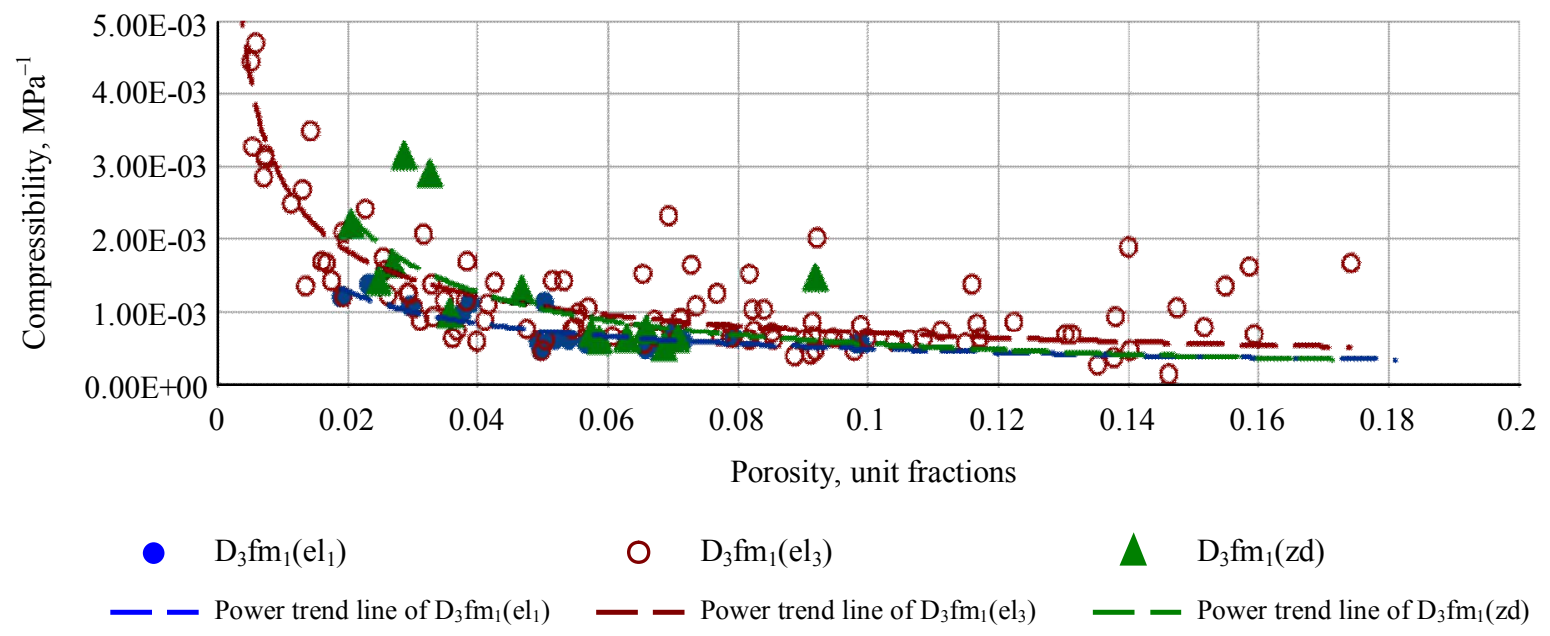

Fig.3. Dependencies of pore space compressibility factor on porosity values under reservoir conditions 
Fig. 3 shows that trend lines of dependencies between compressibility and porosity are different for different layers. Average compressibility values are the following: $\mathrm{D}_{3} \mathrm{fm}_{1}\left(\mathrm{el}_{1}\right)=0.00079$, $\mathrm{D}_{3} \mathrm{fm}_{1}\left(\mathrm{el}_{3}\right)=0.00172, \mathrm{D}_{3} \mathrm{fm}_{1}(\mathrm{zd})=0.00190 \mathrm{MPa}^{-1}$. Using the Student's $t$-test, a statistical comparison of average values of compressibility factor of each of the layers was made. Student's $t$-statistics which allows to compare compressibility values across layers and $p$-value are presented below:

$\begin{array}{cccc}\text { Average value of rock compressibility factor, } \mathrm{MPa}^{-1} & t \text {-statistics } & p \text {-value } \\ 0.00079 & 0.00172 & -1.56 & 0.12 \\ 0.00079 & 0.00190 & -2.27 & 0.02 \\ 0.00172 & 0.00190 & -0.25 & 0.80\end{array}$

Statistically significant difference is observed between average values of the compressibility factor in $\mathrm{D}_{3} \mathrm{fm}_{1}\left(\mathrm{el}_{1}\right)$ and $\mathrm{D}_{3} \mathrm{fm}_{1}(\mathrm{zd})$ layers $(p<0.05)$. On the other hand, the difference between the compressibility values of $\mathrm{D}_{3} \mathrm{fm}_{1}\left(\mathrm{el}_{1}\right)$ and $\mathrm{D}_{3} \mathrm{fm}_{1}\left(\mathrm{el}_{3}\right)$ layers is also quite big $(t=-1.56 ; p=0,12)$, which means that it has to be taken into account. Statistical difference between $\mathrm{D}_{3} \mathrm{fm}_{1}(\mathrm{zd})$ and $\mathrm{D}_{3} \mathrm{fm}_{1}\left(\mathrm{el}_{3}\right)$ layers have not been detected $(t=-0.25 ; p=0.80)$, average values of compressibility factor for both samples are close to one another, which is caused by similarity of porosity parameters for these layer samples. However, in the geological profile $\mathrm{D}_{3} \mathrm{fm}_{1}(\mathrm{zd})$ and $\mathrm{D}_{3} \mathrm{fm}_{1}\left(\mathrm{el}_{3}\right)$ layers are separated by $\mathrm{D}_{3} \mathrm{fm}_{1}\left(\mathrm{el}_{1-2}\right)$ layers, therefore it is wrong to assume that they share the same dependency. Basing on the conducted analysis, a separate dependency was adopted to distribute the compressibility parameter for each layer.
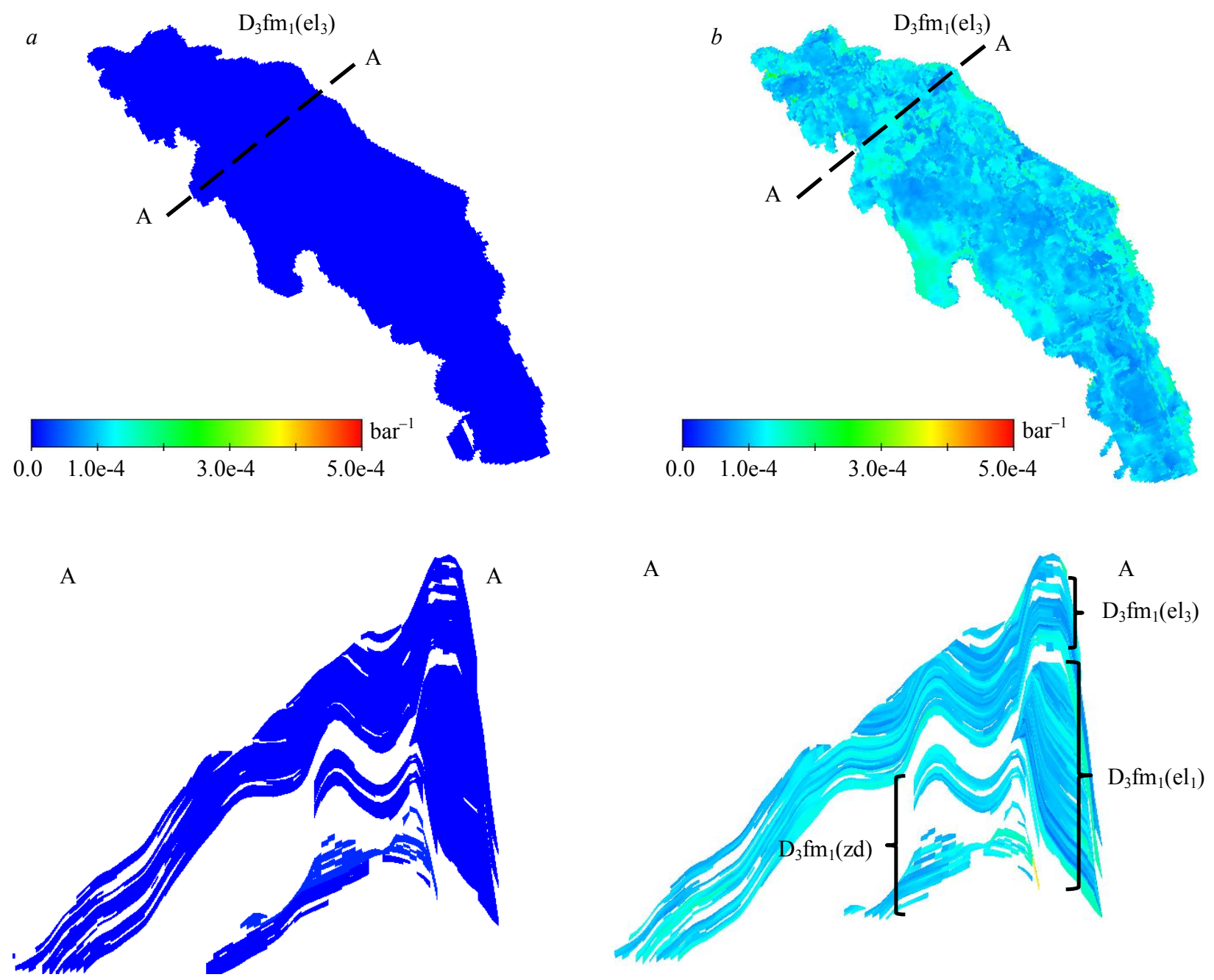

Fig.4. Oil field model visualization, exemplified by the compressibility cube: $a$ - conventional approach; $b$ - approach, taking into account dependency between compressibility and porosity 
Basing on the obtained dependencies, pore space compressibility factor was distributed throughout total volume of productive layers. Fig.4 presents comparative visualization of models with and without regard to compressibility distribution throughout the whole layer.

In geologically complex highly-stratified reservoirs, oil saturated pay zones associated with sub-tight rocks participate in the process of reservoir pressure redistribution due to elastic rock properties. To enhance the physicality of reservoir pressure simulation in the PGTM, a simplified method of sub-tight rock formation was proposed.

At the first stage, for tight (non-reservoir) rocks lithology parameter is set at 0.1 , whereas porosity is assumed to equal its minimal value for reservoir rocks (0.036). At the initial stage of PGTM construction, absolute permeability, both for reservoirs and tight rocks, is estimated by recalculating existing cube of porosity using the "core - geophysical research" dependency $\mathrm{K}_{\mathrm{per}}=f\left(\mathrm{~K}_{\mathrm{por}}\right)$; for Yelets reef sediments, the dependency can be presented as:

$$
\mathrm{K}_{\text {per }}=0.0023 \mathrm{~K}_{\text {por }}^{4.6672} \text {, }
$$

for all other facies zones of Yelets and Zodonian sediments it is should be:

$$
\mathrm{K}_{\text {per }}=0.0006 \mathrm{~K}_{\text {por }}^{4.5296} \text {. }
$$

Sub-tight rock formations, located above the oil-water contact, are assigned the minimal value of oil saturation factor 0.691 . In order to eliminate fluid filtration in sub-tight rocks, values of residual oil and water saturation are adopted, which account for $1 \%$ of the mobile phase. Fig.5 presents a visual comparison of reservoir pressure redistribution, exemplified by the log of well N 2 at the Alpha oil field.

In the construction of a hydrodynamic oil field model, the most important task is to distribute filtration and volumetric properties of the productive layer so that filtration processes correspond to the actual development dynamics as much as possible. [9, 10, 13, 14]. As a result of research published in paper [6], the following processes impact formation of the reservoir useful capacity: recrystallization (formation of additional intercrystalline porosity), leaching (circulation of solutions along weakened zones - formation of secondary voids) and dolomitization (total or partial restructuring of the rocks, i.e. formation of significant intercrystalline porosity). In order to identify the factors, that have the greatest influence on the formation of the fundamental parameter that determines the filtration process, i.e. porosity, statistical analysis of core tests was performed. Key statistical indicators of productive layers were calculated (Table 1).

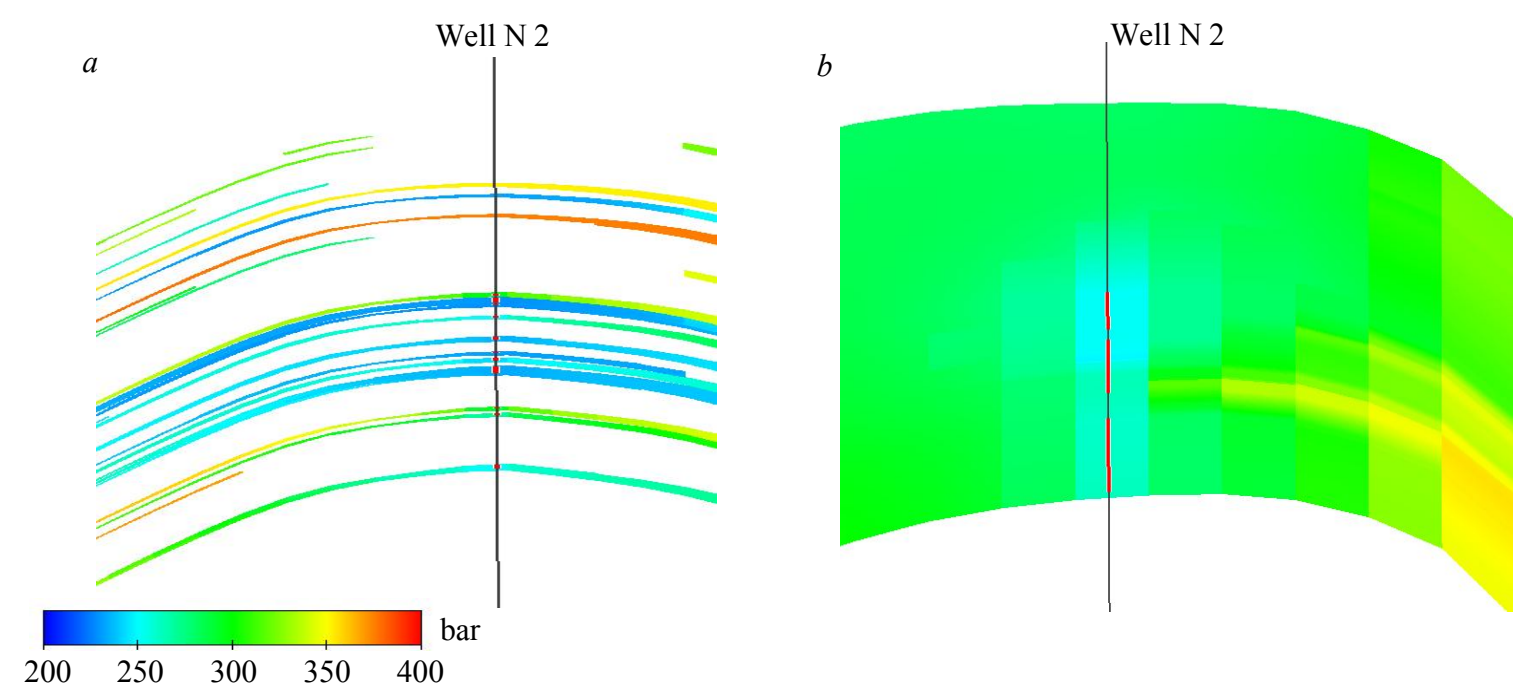

Fig.5. Reservoir pressure distribution: for the model with effective interlayers only $(a)$; with the account of sub-tight rocks $(b)$ 
Key Statistical Indicators of Core Treatment

Table 1

\begin{tabular}{|c|c|c|c|c|c|c|c|c|}
\hline Parameter & Layer & $\begin{array}{l}\text { Number of } \\
\text { observations }\end{array}$ & Average & Min & Max & Dispersion & $\begin{array}{l}\text { Standard } \\
\text { deviation }\end{array}$ & Kurtosis \\
\hline \multirow[t]{3}{*}{ Permeability, $\mu \mathrm{m}^{2} \cdot 10^{-3}$} & $\mathrm{D}_{3} \mathrm{fm}_{1}\left(\mathrm{el}_{1}\right)$ & 976 & 91.8 & 0 & $18,143.0$ & $624,510.4$ & 790.3 & 309.3 \\
\hline & $\mathrm{D}_{3} \mathrm{fm}_{1}\left(\mathrm{el}_{3}\right)$ & 984 & 72.8 & 0 & $9,058.2$ & $191,179.1$ & 437.2 & 234.0 \\
\hline & $\mathrm{D}_{3} \mathrm{fm}_{1}(\mathrm{zd})$ & 1,199 & 8.9 & 0 & 909.5 & $1,780.1$ & 42.2 & 197.0 \\
\hline \multirow[t]{3}{*}{ Density, $\mathrm{g} / \mathrm{cm}^{3}$} & $\mathrm{D}_{3} \mathrm{fm}_{1}\left(\mathrm{el}_{1}\right)$ & 1,025 & 2.6 & 2.0 & 2.8 & 0.0 & 0.1 & 7.4 \\
\hline & $\mathrm{D}_{3} \mathrm{fm}_{1}\left(\mathrm{el}_{3}\right)$ & 1,142 & 2.6 & 2.1 & 2.8 & 0.0 & 0.1 & 0.3 \\
\hline & $\mathrm{D}_{3} \mathrm{fm}_{1}(\mathrm{zd})$ & 1,332 & 2.6 & 2.2 & 2.8 & 0.0 & 0.1 & 0.8 \\
\hline \multirow[t]{3}{*}{ Porosity, unit fractions } & $\mathrm{D}_{3} \mathrm{fm}_{1}\left(\mathrm{el}_{1}\right)$ & 1,025 & 0.05 & 0.001 & 0.29 & 0.11 & 0.03 & 0.06 \\
\hline & $\mathrm{D}_{3} \mathrm{fm}_{1}\left(\mathrm{el}_{3}\right)$ & 1,142 & 0.06 & 0.004 & 0.21 & 0.19 & 0.04 & 0.003 \\
\hline & $\mathrm{D}_{3} \mathrm{fm}_{1}(\mathrm{zd})$ & 1,332 & 0.04 & 0.004 & 0.18 & 0.11 & 0.03 & 0.01 \\
\hline \multirow{2}{*}{ Calcite content, $\%$} & $\mathrm{D}_{3} \mathrm{fm}_{1}\left(\mathrm{el}_{1}\right)$ & 176 & 34.1 & 0.1 & 99.9 & $1,730.8$ & 41.6 & -1.5 \\
\hline & $\mathrm{D}_{3} \mathrm{fm}_{1}\left(\mathrm{el}_{3}\right)$ & 108 & 98.0 & 83.5 & 99.9 & 4.2 & 2.1 & 24.7 \\
\hline \multirow{2}{*}{ Dolomite content, \% } & $\mathrm{D}_{3} \mathrm{fm}_{1}\left(\mathrm{el}_{1}\right)$ & 176 & 65.2 & 0.1 & 99.9 & $1,780.2$ & 42.2 & -1.5 \\
\hline & $\mathrm{D}_{3} \mathrm{fm}_{1}\left(\mathrm{el}_{3}\right)$ & 108 & 2.0 & 0.1 & 13.9 & 3.2 & 1.8 & 18.3 \\
\hline
\end{tabular}

From Table 1 it is clear that reservoir properties of $\mathrm{D}_{3} \mathrm{fm}_{1}\left(\mathrm{el}_{1-3}\right)$ and $\mathrm{D}_{3} \mathrm{fm}_{1}(\mathrm{zd})$ samples differ significantly. The average permeability value is the highest for $\mathrm{D}_{3} \mathrm{fm}_{1}\left(\mathrm{el}_{1}\right) \operatorname{rocks}\left(0.092 \mu \mathrm{m}^{2}\right)$; it is slightly lower for $\mathrm{D}_{3} \mathrm{fm}_{1}\left(\mathrm{el}_{3}\right)$ sample $\left(0.073 \mu \mathrm{m}^{2}\right)$ and for $\mathrm{D}_{3} \mathrm{fm}_{1}(\mathrm{zd})$ layer $\left(0.009 \mu \mathrm{m}^{2}\right)$ it is lower by an order of magnitude. At the same time, $\mathrm{D}_{3} \mathrm{fm}_{1}\left(\mathrm{el}_{1,3}\right)$ and $\mathrm{D}_{3} \mathrm{fm}_{1}\left(\mathrm{el}_{3}\right)$ samples have high values of standard deviation: 780.3 and 437.2, respectively, whereas the same value for $\mathrm{D}_{3} \mathrm{fm}_{1}(\mathrm{zd})$ equals 42.2, which implies heterogeneous permeability of $\mathrm{D}_{3} \mathrm{fm}_{1}\left(\mathrm{el}_{1,3}\right)$ layers and greater persistence of $\mathrm{D}_{3} \mathrm{fm}_{1}$ (zd) layer. Average porosity values are the highest for $\mathrm{D}_{3} \mathrm{fm}_{1}\left(\mathrm{el}_{3}\right)$ sample $(0.05)$, but maximum values correspond to $\mathrm{D}_{3} \mathrm{fm}_{1}\left(\mathrm{el}_{1}\right)$ layer $(0.29) ; \mathrm{D}_{3} \mathrm{fm}_{1}(\mathrm{zd})$ body has the lowest average porosity (0.04). Differences between volume density parameters have not been detected. It should be noted that $\mathrm{D}_{3} \mathrm{fm}_{1}\left(\mathrm{el}_{1}\right)$ and $\mathrm{D}_{3} \mathrm{fm}_{1}\left(\mathrm{el}_{3}\right)$ layers differ significantly in their calcite and dolomite content. In $\mathrm{D}_{3} \mathrm{fm}_{1}\left(\mathrm{el}_{1}\right)$ samples, the dominant mineral is dolomite (average content of $65.2 \%$ ), while calcite is prevalent in $\mathrm{D}_{3} \mathrm{fm}_{1}\left(\mathrm{el}_{3}\right)$ samples (average content of $98 \%$ ). From this it can be concluded that $\mathrm{D}_{3} \mathrm{fm}_{1}\left(\mathrm{el}_{1}\right)$ layer rocks are more subject to secondary alterations and hence they possess higher reservoir properties.

A conventional approach to the development of hydrodynamic models implies that a "core geophysical research" dependency $\mathrm{K}_{\text {per }}=f\left(\mathrm{~K}_{\text {por }}\right)$ is taken into account when constructing a permeability cube. However, frequently the use of this dependency alone does not provide for reconstructing historical data of fluid and oil recovery in the wells of the model [11, 12]. In this paper, for the purpose of additional permeability modification, statistical analysis of core tests was performed to

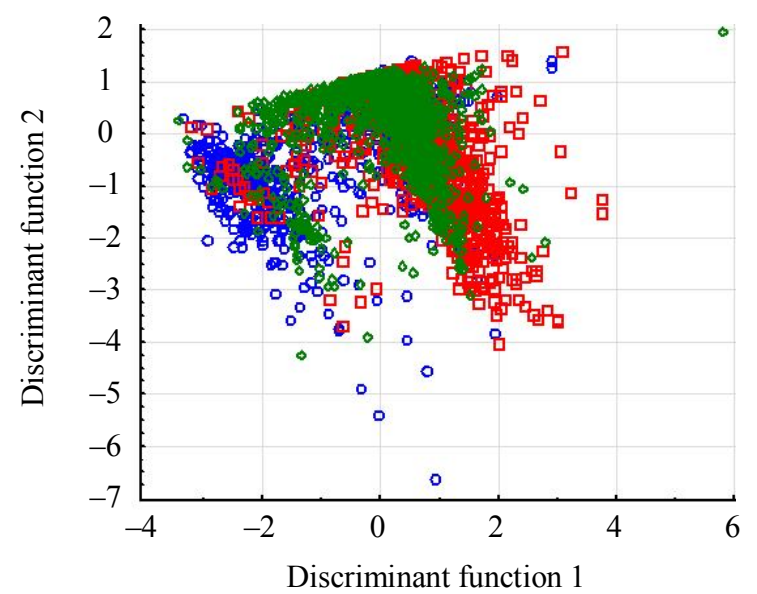

$\circ \mathrm{D}_{3} \mathrm{fm}_{1}\left(\mathrm{el}_{1}\right) \quad \square \mathrm{D}_{3} \mathrm{fm}_{1}\left(\mathrm{el}_{3}\right) \quad \circ \mathrm{D}_{3} \mathrm{fm}_{1}(\mathrm{zd})$

Fig.6. Scatter plot for accepted values construct multidimensional dependencies between various parameters and permeability of each layer.

At the first stage, using the method of linear discriminant analysis, which provides maximum differentiation of samples basing on a set of characteristics, the differences in permeability, porosity and density, calcite and dolomite content were established between $\mathrm{D}_{3} \mathrm{fm}_{1}\left(\mathrm{el}_{1}\right), \mathrm{D}_{3} \mathrm{fm}_{1}\left(\mathrm{el}_{3}\right)$ and $\mathrm{D}_{3} \mathrm{fm}_{1}(\mathrm{zd})$ layers. Classification results are presented in Fig.6. It is evident from the Figure that selected characteristics vary significantly across the samples. A distinct classification into three various groups is observed, discrepancy in all the parameters is statistically significant $(p<0.05)$

Further, in order to implement a more detailed approach to the bulk distribution of permeability in the PGTM volume, multidimensional dependencies allowing to estimate the impact of the parameter complex on 
permeability, were plotted for each layer. Multidimensional dependencies were plotted by means of stepwise multiple regression, where each step implied inclusion of significant parameters into the model. Parameters taken into account included porosity, density, calcite and dolomite content in the rocks. Reliability of the statistical model was estimated with a coefficient of multiple correlation $R$ and $p$-value. As a result, the following dependencies were obtained for each layer:

$$
\begin{gathered}
\mathrm{D}_{3} \mathrm{fm}_{1}\left(\mathrm{el}_{1}\right): \mathrm{K}_{\mathrm{per}}=434 \mathrm{~K}_{\mathrm{por}}+15.1 \mathrm{Calc}+4,722 \rho-21,181 \text { at } n=171 ; R=0.68 ; p<10^{-4} ; \\
\mathrm{D}_{3} \mathrm{fm}_{1}\left(\mathrm{el}_{3}\right): \mathrm{K}_{\text {per }}=410 \mathrm{~K}_{\text {por }}+7,604 \rho-20,882 \text { at } n=78 ; R=0.58 ; p<0.0005 ; \\
\mathrm{D}_{3} \mathrm{fm}_{1}(\mathrm{zd}): \mathrm{K}_{\text {per }}=6 \mathrm{~K}_{\text {por }}+62.3 \rho+177 \text { at } n=318 ; R=0.53 ; p<0.0000,
\end{gathered}
$$

where $\rho$ is rock density, $\mathrm{kg} / \mathrm{m}^{3} \cdot 10^{-3}$; Calc is calcite content, \%; $n$ is the number of values in the model construction.

For each layer, parameters that have an impact on permeability formation were taken into account. For $\mathrm{D}_{3} \mathrm{fm}_{1}\left(\mathrm{el}_{1}\right)$ rocks, the substantial parameters included porosity, calcite content, and rock density, which can be explained by the presence of paleokarst and a large number of cavities. Dolomite content did not have any statistically significant impact on permeability, which demonstrated a profound influence of leaching on filtration characteristics of the layer. Permeability of $\mathrm{D}_{3} \mathrm{fm}_{1}\left(\mathrm{el}_{3}\right)$ and $\mathrm{D}_{3} \mathrm{fm}_{1}(\mathrm{zd})$ layers formed under the influence of porosity and density. These rocks are to a lesser extent subject to secondary processes, hence the calcite and dolomite content did not have any statistically significant impact on the absolute permeability.

Obtained dependencies (2)-(4) allow to extrapolate absolute permeability throughout the whole volume of layers under consideration. In order to do that, at the first stage the cubes of properties were constructed by means of bulk parameter interpolation, using the curves of porosity, density and calcite content in the rocks, calibrated against data from core tests. Then, basing on the obtained dependencies, absolute permeability was recalculated for all layers (Fig.7).

Results. At the final stage of the research, efficiency of the proposed method was tested. Convergence with the actual data was estimated for a conventional PGTM and for the model constructed as part of this study (Table 2). The task was performed only once, no additional matching of the PGTM was carried out.

Basing on the performed calculations, convergence of the PGTM with the actual data on accumulated oil and fluid production increased by $24.9 \%$ and $9.9 \%$, respectively. Moreover, a significant increase in the convergence of reservoir pressure dynamics compared to the actual data was observed (Fig.8).

In the course of the study, an analysis of geological structure of the multi-layer Alpha oil field was conducted and a necessity to take into account geomechanical properties and structural irregularities in the process of geological and hydrodynamic model construction was identified. To take into account the compressibility parameter, an acceptable range of effective pressures was identified. Compression test results for 178 core samples were analyzed and dependencies between compressibility and porosity were plotted in the acceptable range. Using methods of mathematical statistics, it was demonstrated that compressibility should be considered separately for each productive
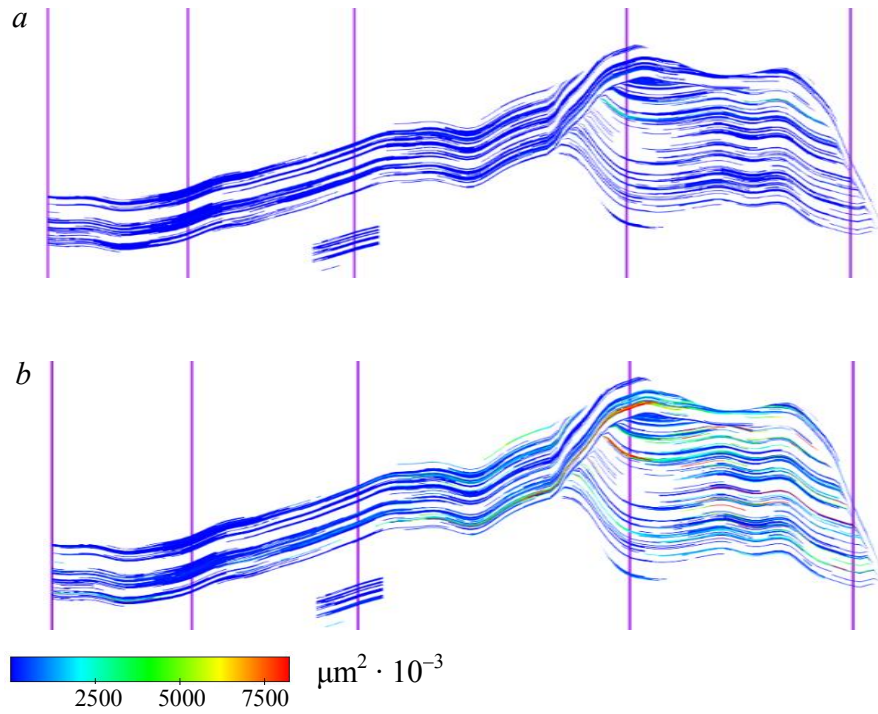

Fig.7. Arbitrary geological profile in case of absolute permeability cube: model without modifications $(a)$; model with additional modifications $(b)$ 
Comparative Analysis between PGTM and Actual Accumulated Oil Production

\begin{tabular}{l|c|c|c|c|c|c}
\hline \multirow{2}{*}{$\begin{array}{c}\text { PGTM construction } \\
\text { method }\end{array}$} & \multicolumn{2}{|c|}{ Accumulated oil production, thousand tons } & \multicolumn{3}{c}{ Accumulated fluid production, thousand tons } \\
\cline { 2 - 6 } & Actual & Estimated & Error, \% & Actual & Estimated & Error, \% \\
\hline Without modifications & $11,992.0$ & $\begin{array}{l}6,874.2 \\
9,854.7\end{array}$ & $\begin{array}{l}42.7 \\
17.8\end{array}$ & $12,839.4$ & $\begin{array}{c}9,998.4 \\
11,853.2\end{array}$ \\
With modifications & & & 12.2 &
\end{tabular}

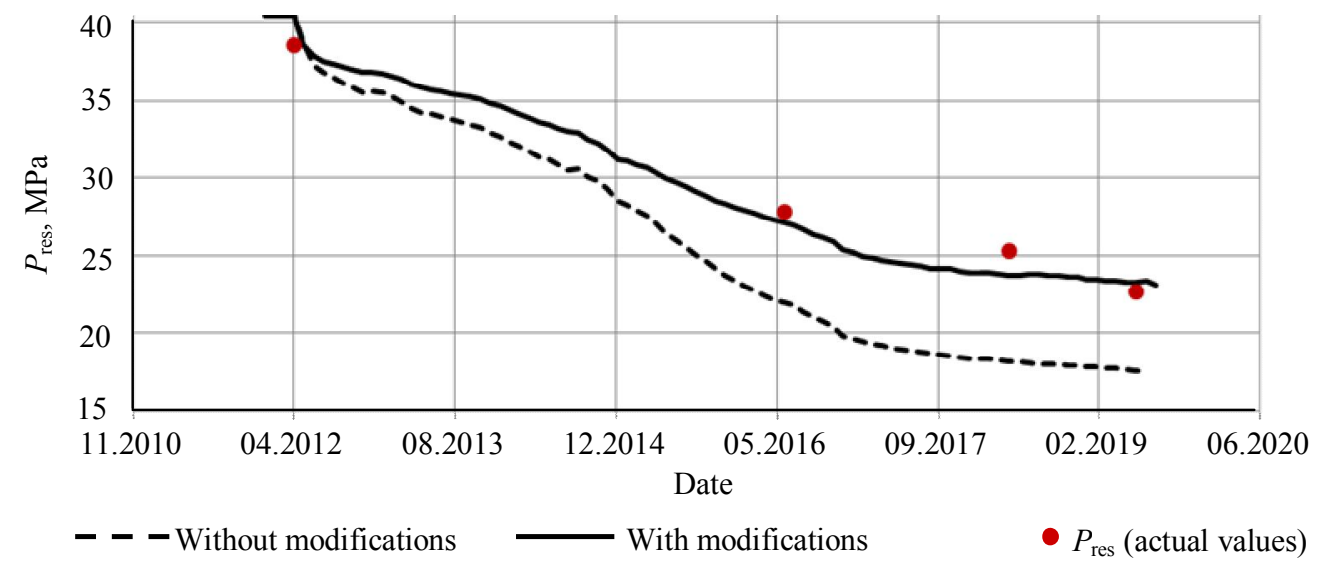

Fig.8. Comparison between estimated and actual reservoir pressure for well N 2 at the Alpha oil field

layer. To enhance physicality of reservoir pressure distribution under the conditions of highly stratified reservoirs, elastic properties of dense rocks were taken into account by including sub-tight rocks into the model. In order to specify filtration characteristics of the layers, such properties of core samples as permeability, porosity, density, calcite and dolomite content were closely analyzed. It was established that the best filtration and volumetric characteristics were observed in $\mathrm{D}_{3} \mathrm{fm}_{1}\left(\mathrm{el}_{1}\right)$ reservoirs, whereas the worst ones were identified in $\mathrm{D}_{3} \mathrm{fm}_{1}(\mathrm{zd})$ layer.

In order to construct a permeability cube of structurally complex reservoirs, multidimensional dependencies between permeability and a set of parameters (porosity, density, calcite and dolomite content) were separately used for each productive layer, which allowed to take into account heterogeneity of geology and the impact of secondary processes on the permeability parameter. Results of modified model calibration against the actual data were compared to the model without modifications. As a result, the model was successfully calibrated against the history of reservoir pressure changes, the quality of calibration against the data on fluid and oil production has also dramatically increased.

Conclusions. Application of the proposed approach allowed to simplify the adaptation of geological and hydrodynamic models to the actual development parameters. Discretization of pore space compressibility parameter as a function of porosity, as well as inclusion of sub-tight rocks into the model, allowed to enhance the reality level of the reservoir pressure distribution throughout the PGTM and to reproduce the actual history of production facility development with a high convergence. Distribution of absolute permeability, dependent on a set of parameters, provided for a high-precision reproduction of filtration processes, characteristic for structurally complex reservoirs, which significantly improved PGTM quality at the oil field in question and, consequently, the quality of short- and long-term forecasts.

Taking into account the geomechanical properties in the model according to the method, described in this paper, did not lead to any changes in the computational speed, which became a significant advantage compared to full-scale geomechanical models, the computations of which can last up to six days. 
In subsequent research, the authors of the paper plan to use machine learning algorithms in order to increase precision of the geological base and to reduce subjectivity of the model in the process of parameter distribution in the interwell space.

\section{REFERENCES}

1. Alchibaev D.V., Glazyrina A.E. The Role of 3D Geomechanical Modelling in the Development of Severo-Samburgskoye Field. PROneft. 2018. N 4, p. 56-59. DOI: 10.24887/2587-7399-2018-4-56-59 (in Russian).

2. Kashnikov Yu.A., Ashikhmin S.G., Shustov D.V., Yakimov S.Yu., Kukhtinskii A.E. Efficiency Improvement of Hydrocarbon Field Development Based on Complex Geomechanical Studies. Neftyanoe khozyaistvo. 2019. N 3, p.66-69. DOI: 10.24887/0028-2448-2019-3-66-69 (in Russian).

3. Martyushev D.A., Lekomtsev A.V., Kotousov A.G. Assessment of Opening and Compressibility of Natural Fractures in the Carbonate Formation of the Logovsky Deposit. Vestnik Permskogo natsionalnogo issledovatelskogo politekhnicheskogo universiteta. Geologiya. Neftegazovoe i gornoe delo. 2015. N 16, p. 61-69 (in Russian).

4. Karev V.I., Kovalenko Yu.F., Zhuravlev A.B., Ustinov K.B. Model of Well Filtration Taking into Account Dependency between Permeability and Stress. Protsessy v geosredakh. 2015. N 4, p. 34-44 (in Russian).

5. Gurbatova I.P., Plotnikov V.V., Popov N.A., Sysoev I.V. Specific Features of Studying Filtration Characteristics of Oriented Core in Structurally Complex Carbonate Reservoirs.. Vestnik Permskogo natsionalnogo issledovatelskogo politekhnicheskogo universiteta. Geologiya. Neftegazovoe i gornoe delo. 2013. N 9, p. 79-86 (in Russian).

6. Popov N.A., Plyusnin A.V., Staroverova A.Yu. Lithotype Characteristics of Late-Devonian Reefogenic Structures of the Denisov Depression. Tezisy dokladov XXI Gubkinskikh chtenii "Fundamentalnyi bazis innovatsionnykh tekhnologii poiskov, razvedki i razrabotki mestorozhdenii nefti i gaza i prioritetnye napravleniya razvitiya resursnoi bazy TEK Rossii”, 24-25 marta 2016, RGU nefti i gaza (NIU) im. I.M.Gubkina, 2016, p. 248-253 (in Russian).

7. RD 153-39-007-96 Procedure for the Preparation of Design Technological Documents for the Development of Oil and Oil \& Gas Fields (in Russian).

8. Sobolev A.A. A Review of the World Practice on geological and Geomechanical Modelling. Nauchnyi zhurnal. 2016. N 12, p. 17-18 (in Russian).

9. Barletta A. Fluid Flow in Porous Media. Routes to Absolute Instability in Porous Media. Cham, Switzerland: Springer, 2019, p. 121-133.

10. Ngoc T.B. Nguyen, Cuong T.Q. Dang, Chaodong Yang, Long X. Nghiem, Zhangxin Chen. Integrated Static and Dynamic Big-Loop Modeling Workflow for Assisted History Matching of SAGD Process with Presence of Shale Barriers. SPE Canada Heavy Oil Technical Conference, 13-14 March 2018, Calgary, Alberta, Canada, p. 30-50. DOI: 10.2118/189725-MS

11. Jef Caers. Geostatistical History Matching Under Training-Image Based Geological Model Constraints. SPE Annual Technical Conference and Exhibition, 29 September - 2 October 2002, San Antonio, Texas, USA. DOI: 10.2118/77429-MS

12. Jeroen C. Vink., Guohua Gao, Chaohui Chen. Bayesian Style History Matching: Another Way to Under-Estimate Forecast Uncertainty? SPE Annual Technical Conference and Exhibition, 28-30 September 2015, Houston, Texas, USA, p. 19. DOI: $10.2118 / 175121-\mathrm{MS}$

13. Putilov I., Krivoshchekov S., Vyatkin K., Kochnev A., Ravelev K. Methods of predicting the effectiveness of hydrochloric acid treatment using hydrodynamic simulation. Applied Sciences. 2020. Vol. 10. Iss. 14. DOI:10.3390/app10144828

14. Numbere D.T., Erkal A. A model for Tracer Flow in Heterogeneous Porous Media. SPE Asia Pacific Conference on Integrated Modelling for Asset Management, 23-24 March 1998, Kuala Lumpur, Malaysia, 1998. P. 37-44. DOI: 10.2118/39705-MS

15. Shapiro S.A., Khizhniak G.P., Plotnikov V.V., Niemann R., Ilushin P.Yu., Galkin S.V. Permeability dependency on stiff and compliant porosities: a model and some experimental examples. Journal of Geophysics and Engineering. 2015. Vol. 12. N 3, p. 376-385. DOI: $10.1088 / 1742-2132 / 12 / 3 / 376$

16. Shapiro S.A., Khizhniak G.P., Plotnikov V.V., Niemann R., Ilushin P.Y., Galkin S.V. Stiff- and compliant-porosity based model of permeability - Theory and experiments: Conference Proceedings. 77th EAGE Conference and Exhibition, 1-4 June 2015, Madrid, 2015. P. 2812-2816. DOI: 10.3997/2214-4609.201412949

Authors: Sergey V. Galkin, Doctor of Geology and Mineralogy,Professor,doc_galkin@mail.ru (Perm National Research Polytechnic University, Perm, Russia), Sergey N. Krivoshchekov, Candidate of Engineering, Associate Professor, krivoshchekov @gmail.com (Perm National Research Polytechnic University, Perm, Russia), Nikita D. Kozyrev, Postgraduate Student, nikitonkozyrev@gmail.com (Perm National Research Polytechnic University, Perm, Russia), Alexander A. Kochnev, Postgraduate Student, sashakoch93@gmail.com (Perm National Research Polytechnic University, Perm, Russia), Alexander G. Mengaliev, Engineer, mengaliev.alexandr@gmail.com (Branch of LLC LUKOIL-Engineering PermNIPIneft, Perm, Russia).

The paper was received on 23 April, 2020.

The paper was accepted for publication on 03 May, 2020. 